\title{
Determinacy of equilibrium in a New Keynesian model with monetary policy lag
}

\author{
Eiji Tsuzuki \\ Faculty of Economics, Chiba Keizai University, Chiba, Japan
}

Email address:

tsuzukie5@gmail.com

To cite this article:

Eiji Tsuzuki. Determinacy of Equilibrium in a New Keynesian Model with Monetary Policy Lag. International Journal of Economic Behavior and Organization. Special Issue: Recent Developments of Economic Theory and Its Applications. Vol. 3, No. 2-1, 2015 , pp. 15-22.

doi: $10.11648 /$ j.ijebo.s.2015030201.14

\begin{abstract}
We use the New Keynesian continuous-time framework to theoretically investigate the effects of a lag in a central bank's response to economic fluctuations (i.e., monetary policy lag) on local equilibrium determinacy. In the case of a policy without lag, equilibrium is indeterminate even though a central bank's policy response is sufficiently active. However, in the case of a policy with lag, an active monetary policy can contribute to local equilibrium determinacy if the lag is modest.
\end{abstract}

Keywords: Money in the Production Function (MIPF) Model, Policy Lag, System of Delay Differential Equations, Monetary Policy Rule, Taylor Principle

\section{Introduction}

Many studies have examined equilibrium determinacy in the New Keynesian (NK) model. The NK model has a dynamic stochastic general equilibrium (DSGE) framework that incorporates factors pertaining to the stickiness of both prices and wages. The standard NK model derives a well-known monetary policy norm called the Taylor principle: the central bank should increase (decrease) the nominal interest rate by more than a one-for-one ratio in response to an increase (decrease) in the inflation rate. ${ }^{1}$

Bernanke and Woodford [5], Carlstrom and Fuerst [9], and Benhabib, Schmitt-Grohé and Uribe [3, 4] consider a situation where the nominal interest rate is changed in response to past inflation rates, a policy rule called the backward-looking interest-rate rule. Moreover, they consider a situation where the nominal interest rate is changed in response to future anticipated inflation rates, called the forward-looking interest-rate rule. A series of their studies reveals that the backward-looking interest-rate rule increases the possibility of equilibrium determinacy, whereas the forward-looking interest-rate rule may decrease this possibility.

\footnotetext{
${ }^{1}$ This is derived from Taylor [19]. Woodford [24], Gali [15], and Walsh [23] are introductory textbooks to the NK model.
}

Furthermore, Bilbiie [6] considers the existence of limited asset market participation in a standard cashless NK model. On the basis of this assumption, he demonstrates that equilibrium can be locally determinate even if the Taylor principle does not hold. However, Buffie [8] indicates that this result is strongly dependent on the assumption that real wages are highly flexible. If this assumption is relaxed, then the Taylor principle reasserts itself as a necessary and sufficient condition for local determinacy.

Thus, while the effects of monetary policies on economic stability (i.e., equilibrium determinacy) have been intensively explored in recent years, ${ }^{2}$ few studies have examined policy lags. Friedman [14] notably examines the effects of policy lags on economic stability but does not develop a theoretical analysis.

Asada and Yoshida [1] and Yoshida and Asada [25] theoretically investigate the impacts of a fiscal policy lag on economic stability using descriptive frameworks that do not have micro-foundations. Moreover, Tsuzuki [21] examines the effects of a monetary policy lag using an NK model with

\footnotetext{
${ }^{2}$ Carlstrom and Fuerst [11] and Tsuzuki [22] consider a rule wherein the nominal interest rate is changed not in response to the inflation rate but to asset prices. Such a rule represents the practice of asset-price targeting. Carlstrom and Fuerst [11] show that asset-price targeting increases the possibility of indeterminacy; however, Tsuzuki [22] shows that Carlstrom and Fuerst's [11] result can be overturned by introducing technological changes induced by educational investment.
} 
the assumption of money in the utility function (MIUF). These studies obtain the same conclusion, i.e., a policy lag causes economic instability.

This study uses an NK model that adopts the assumption of money in the production function (MIPF) based on Benhabib, Schmitt-Grohé and Uribe [4] in order to analyze the effects of a monetary policy lag as in Tsuzuki [21]. This minor change vastly alters the model's dynamic property and yields a major implication: a policy lag can contribute to local equilibrium determinacy.

This study proceeds as follows: Section 2 presents a set of fundamental equations for the model economy. Section 3 analyzes the normal case in which a policy lag does not exist. Section 4 analyzes the case in which a monetary policy lag exists. Section 5 presents our conclusion.

\section{The Model}

We now present a standard NK MIPF framework. The model economy is compounded from household-firm units $i$ $(i \in[0,1])$, the central bank, and the government. Firm $i$ produces a differentiated good $i$ with an input of money. Households aggregate various types of differentiated goods and consume them.

\subsection{Intratemporal Optimization}

Households aggregate differentiated goods via the Dixit-Stiglitz function: ${ }^{3}$

$$
y=\left[\int_{0}^{1} y_{i}^{\frac{\phi-1}{\phi}} d i\right]^{\frac{\phi}{\phi-1}}
$$

where $y$ is the volume of the composite good; $y_{i}$ is the volume of good $i$; and $\phi(>1)$ is the elasticity of substitution among differentiated goods.

Given the price of good $i, p_{i}$, the price of composite goods $p$, and the volume of composite goods $y$, each household then determines the volume of $y_{i}$ that minimizes the total cost $\int_{0}^{1} p_{i} y_{i} d i$. The first-order condition for cost minimization is given as follows:

$$
y_{i}=\left(\frac{p_{i}}{p}\right)^{-\phi} y
$$

where $p$ is the price level, which is given by

$$
p=\left[\int_{0}^{1} p_{i}^{1-\phi} d i\right]^{\frac{1}{1-\phi}}
$$

\subsection{Intertemporal Optimization}

We formulate the producing technology of firm $i$ as follows:

$$
y_{i}=m_{i}^{\alpha},
$$

where $m_{i}$ is the real cash balance required to produce good $i$,

${ }^{3}$ See Dixit and Stiglitz [12] and Blanchard and Kiyotaki [7]. and $0<\alpha<1$

Household-firm unit $i$ obtains utility from consumption $c_{i}$ and disutility from price revisions $\pi_{i} \equiv \dot{p}_{i} / p_{i}$. For simplicity, we assume that price revisions incur costs only when prices change at a rate different from the steady-state value $\pi^{*}$. The utility function of household-firm unit $i$ can thus be represented as follows:

$$
\ln c_{i}-\frac{\eta}{2}\left(\pi_{i}-\pi^{*}\right)^{2}
$$

where $\eta(>0)$ denotes price stickiness: the larger the value of $\eta$, the stickier the price. We followed Rotemberg's [18] formulation of price revision costs, namely, a quadratic function.

Assuming that the assets held by household-firm unit $i$, denoted by $A_{i}$, are composed of money $M_{i}$ and bonds $B_{i}$, we obtain

$$
A_{i}=M_{i}+B_{i}
$$

We also assume that the government collects a lump-sum tax $X$ from household-firm units. Accordingly, assets increase with rises in income and interest but decrease with consumption and tax, and hence, we obtain

$$
\dot{A}_{i}=p_{i} y_{i}+R B_{i}-p c_{i}-p X
$$

where $R$ is the nominal interest rate for bonds.

Rewriting (3) in real terms, we obtain

$$
\dot{a}_{i}=\frac{p_{i}}{p} y_{i}+r a_{i}-c_{i}-X-R m_{i}
$$

where $a_{i}=A_{i} / p$ is real asset balances; and $r=R-\pi$ is the real interest rate.

The government's intertemporal budget constraint is represented as follows:

$$
X=R \frac{B}{p}
$$

which implies that government policy is of a Ricardian type (see Benhabib, Schmitt-Grohé and Uribe [4, Section 1.2] for details).

Household-firm unit $i$ determines the sequences of $c_{i}$ and $\pi_{i}$, subject to the demand function for good $i$ in (1), the production function in (2), and the budget constraint in (4), that will maximize the discounted present value of a utility stream given as follows:

$$
U_{i}=\int_{0}^{\infty}\left[\ln c_{i}-\frac{\eta}{2}\left(\pi_{i}-\pi^{*}\right)^{2}\right] e^{-\rho t} d t,
$$

where $\rho(>0)$ is the household-firm units' subjective discount rate.

Let us define the Hamiltonian function as follows:

$$
\mathcal{H} \equiv \ln c_{i}-\frac{\eta}{2}\left(\pi_{i}-\pi^{*}\right)^{2}
$$

${ }^{4}$ These costs can be interpreted as psychological stresses caused by price negotiations. 
$+\mu_{1}\left[\frac{p_{i}}{p}\left(\frac{p_{i}}{p}\right)^{-\phi} y+r a_{i}-c_{i}-X-R\left\{\left(\frac{p_{i}}{p}\right)^{-\phi} y\right\}^{\frac{1}{\alpha}}\right]+\mu_{2} \pi_{i} p_{i}$

where $\mu_{1}$ and $\mu_{2}$ are the co-state variables of state variables $a_{i}$ and $p_{i}$, respectively.

The first-order conditions for optimality are given as follows:

$$
\begin{gathered}
\frac{\partial \mathcal{H}}{\partial c_{i}}=\frac{1}{c_{i}}-\mu_{1}=0, \\
\frac{\partial \mathcal{H}}{\partial \pi_{i}}=-\eta\left(\pi_{i}-\pi^{*}\right)+\mu_{2} p_{i}=0, \\
\dot{\mu}_{1}=\rho \mu_{1}-\frac{\partial \mathcal{H}}{\partial a_{i}}=(\rho-r) \mu_{1},
\end{gathered}
$$

$\dot{\mu}_{2}=\rho \mu_{2}-\frac{\partial \mathcal{H}}{\partial p_{i}}=\rho \mu_{2}-\mu_{1}\left[(1-\phi) \frac{y_{i}}{p}+\phi R \frac{1}{\alpha} y_{i}^{\frac{1}{\alpha}-1} \frac{y_{i}}{p_{i}}\right]-\mu_{2} \pi_{i}$.

The transversality conditions are given as follows:

$$
\begin{aligned}
& \lim _{t \rightarrow \infty} a_{i}(t) e^{-\rho t}=0, \\
& \lim _{t \rightarrow \infty} p_{i}(t) e^{-\rho t}=0 .
\end{aligned}
$$

Applying the symmetry condition, we drop subscript $i$ from $c_{i}, y_{i}, p_{i}$, and $\pi_{i}$. Then (5)-(8) can be summarized in the following equations:

$$
\text { Euler equation: } \frac{\dot{c}}{c}=R-\pi-\rho,
$$

$$
\text { Phillips curve: } \dot{\pi}=\rho\left(\pi-\pi^{*}\right)-\frac{(1-\phi) y}{\eta c}-\frac{\phi R y^{\frac{1}{\alpha}}}{\eta \alpha c} \text {. }
$$

\subsection{Monetary Policy}

\subsubsection{Generalized Interest-Rate Rule}

The generalized interest-rate rule, which assumes that the nominal interest rate $R$ responds to the weighted mean of past and present inflation rates, can be represented as follows:

$$
R=R^{*}+D\left(\int_{-\infty}^{t} \pi(s) \delta(s) d s-\pi^{*}\right)
$$

where $R^{*}$ is the targeted level of the nominal interest rate; $\pi^{*}$ is the target inflation rate level (= steady-state value of the inflation rate); and $D(>0)$ is the elasticity of the nominal interest rate with respect to the inflation rate. Accordingly, if $D>1$, then monetary policy is active, whereas if $D<1$, it is passive. The function $\delta(s)$ is the weighting factor of a stream of past and present inflation rates, $\int_{-\infty}^{t} \pi(s) d s$, and is given by

$$
\delta(s)=\left(\frac{n}{\theta}\right)^{n} \frac{(t-s)^{n-1}}{(n-1) !} e^{-\frac{n}{\theta}(t-s)} .
$$

This function can also be interpreted as a density function with the property of $\int_{-\infty}^{t} \delta(s) d s=1$, where the mean is $\theta$ and the variance is $\theta^{2} / n$. Note that $n$ takes positive integer numbers and $\theta>0$.

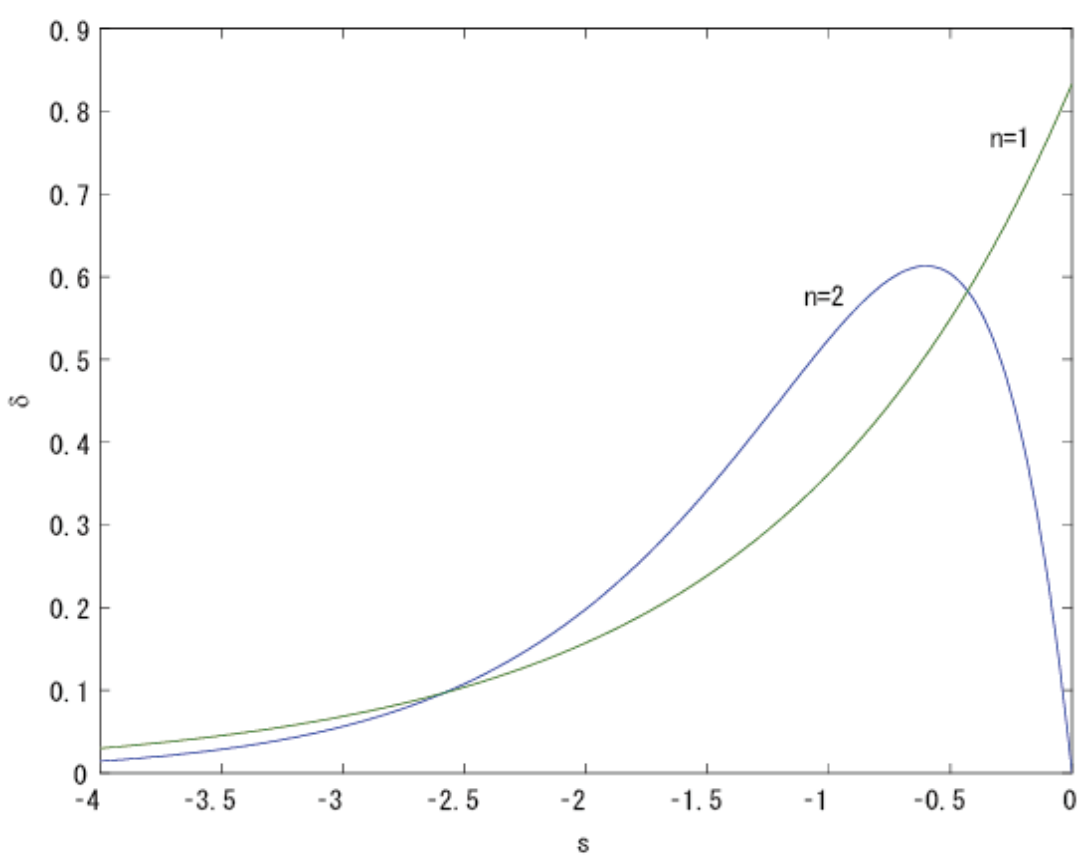

Figure 1. Function $\delta(s)$.

When $n \rightarrow 1, \delta(s)$ becomes an exponential function, $(1 / \theta) e^{-(1 / \theta)(t-s)}$ (see Fig. 1). ${ }^{5}$ The model of Benhabib, Schmitt-Grohé and Uribe [4, Section 2] corresponds to this

${ }^{5}$ We assume $\theta=1.2$ and $t=0$. case. When $n \geq 2, \delta(s)$ becomes a unimodal function that reaches a maximum at $s=t-(n-1) \theta / n,{ }^{6}$ and when

\footnotetext{
${ }^{6}$ Tsuzuki [20] compares cases where $n=2$ and $n=3$. He numerically demonstrates that local determinacy can be established with smaller values of $\theta$ for $n=3$ in comparison for the case of $n=2$.
} 
$n \rightarrow \infty$, it becomes a density function with zero variance; that is, $\delta(s)$ becomes a vertical line at $t-\theta$.

\subsubsection{Normal Interest-Rate Rule}

The normal interest-rate rule assumes that the nominal interest rate $R$ responds to the current inflation rate $\pi$, corresponding to the case where $n \rightarrow \infty$ and $\theta \rightarrow 0$ in (11); that is

$$
R=R^{*}+D\left(\pi-\pi^{*}\right) \text {. }
$$

\subsubsection{Interest-Rate Rule with Policy Lag}

When $n \rightarrow \infty$ and $\theta>0$ in (11), then the interest-rate rule can be represented as follows:

$$
R(t)=R^{*}+D\left(\pi(t-\theta)-\pi^{*}\right) .
$$

We can consider this equation as depicting the situation of a fixed policy lag in the normal interest-rate rule in (12); in other words, a time lag of $\theta>0$ exists in the interest rate's response to business fluctuations.

\section{Case of No Policy Lag}

\subsection{Case with the Interest-Rate Rule in (12)}

Considering the goods market equilibrium condition of $y=c$, the model economy represented by (9), (10), and (12) can then be summarized in the following system of differential equations:

$$
\begin{gathered}
\dot{c}=\left[R^{*}+D\left(\pi-\pi^{*}\right)-\pi-\rho\right] c, \\
\dot{\pi}=\rho\left(\pi-\pi^{*}\right)-\frac{1-\phi}{\eta}-\frac{\phi}{\eta \alpha}\left[R^{*}+D\left(\pi-\pi^{*}\right)\right] c \frac{1-\alpha}{\alpha} .
\end{gathered}
$$

The steady-state values of system (14) are given as follows:

$$
c^{*}=\left(\frac{\phi-1}{\phi \alpha^{-1} R^{*}}\right)^{\frac{\alpha}{1-\alpha}}, \pi^{*}=R^{*}-\rho .
$$

In $\mathrm{NK}$ economics, the concepts of equilibrium determinacy and indeterminacy are used as the stability criteria. NK scholars first distinguish two types of variables: the jump variable and the non-jump variable. If economic agents can arbitrarily determine the initial value of a variable, then that variable is considered a jump variable. In contrast, if the initial value is historically given and cannot be determined by economic agents, then this variable is a non-jump variable. Second, NK experts consider the uniqueness of the equilibrium path. If a candidate for the equilibrium path that converges to or on the steady state uniquely exists, then the equilibrium is determinate; however, if multiple paths can exist, then the equilibrium is indeterminate.

Previous studies have demonstrated that local determinacy around the steady state of system (14) is given by the following proposition (proof is presented in Appendix A.1):

Proposition 3.1 Under the interest-rate rule in (12), if $\rho>P_{2} D$ and $D>1$, then equilibrium is locally determinate, where $P_{2} \equiv \frac{\phi}{\eta \alpha}\left(c^{*}\right)^{\frac{1-\alpha}{\alpha}}>0$; however, if $\rho<P_{2} D$ and
$D>1$, or $D<1$, then equilibrium is indeterminate. ${ }^{7}$

In an NK model that adopts the MIUF approach, which corresponds to the case in which $P_{2}=0$ in our model, the necessary and sufficient condition for local equilibrium determinacy is given by $D>1$, which is the so-called Taylor principle. On the other hand, in our model (adopting the MIPF approach), condition $D>1$ is not the only necessary condition; $\rho>P_{2} D$ is also required to hold for local equilibrium determinacy. ${ }^{8}$

\subsection{Quantitative Analysis of Parameter Constraints}

Table 1. Parameter values (quarter)

\begin{tabular}{llllll}
\hline & $\boldsymbol{\alpha}$ & $\boldsymbol{\phi}$ & $\boldsymbol{\rho}$ & $\boldsymbol{\eta}$ \\
\hline 0.6 & 21 & & 0.005 & 200 & \\
\hline
\end{tabular}

Following Benhabib, Schmitt-Grohé and Uribe [4], let us assume plausible parameter values as shown in Table 1 and further assume that $R^{*}=0.015$. Under this specification, we can calculate the value of $\rho / P_{2}$ as 0.00075 . Therefore, we can assume that inequality $\rho<P_{2} D$ generally holds.

Thus, equilibrium is generally indeterminate even if the central bank's policy stance is sufficiently active. In the following section, however, we show that an active policy stance can contribute to local determinacy if a monetary policy lag exists.

\section{Case of a Positive Policy Lag}

\subsection{Case with the Interest-Rate Rule in (13)}

Using (13) instead of (12), the model economy would then be represented by the following system of delay differential equations:

$$
\begin{aligned}
\dot{c}(t)= & {\left[R^{*}+D\left(\pi(t-\theta)-\pi^{*}\right)-\pi(t)-\rho\right] c(t), } \\
\dot{\pi}(t)= & \rho\left(\pi(t)-\pi^{*}\right)-\frac{1-\phi}{\eta} \\
& -\frac{\phi}{\eta \alpha}\left[R^{*}+D\left(\pi(t-\theta)-\pi^{*}\right)\right] c(t)^{\frac{1-\alpha}{\alpha}} .
\end{aligned}
$$

The steady-state values of system (16) are given in (15). To analyze the local dynamics, we linearize system (16) around

\footnotetext{
${ }^{7}$ Considering $D$ (representing the activeness of monetary policy) as a bifurcation parameter, a Hopf bifurcation occurs at $D=D_{H} \equiv \rho / P_{2}$ under the condition that $D>1$; i.e., the following conditions of the Hopf bifurcation theorem are satisfied at $D=D_{H}$ : (a) $\operatorname{trace}\left(J_{1}\right)=0$ and (b) $d \operatorname{trace}\left(J_{1}\right) / d D \neq 0$ (see Gandolfo [16, Section 16] for details of the theorem). Therefore, for a certain region of $D$ in the neighborhood of $D_{H}$, cycles exist around the steady state. If cycles exist for $D<D_{H}$, they are stable (case of supercritical bifurcation); however, if cycles exist for $D>D_{H}$, they are unstable (case of subcritical bifurcation). It is worth noting that equilibrium is locally determinate but globally indeterminate in the former case. This result was first shown by Benhabib, Schmitt-Grohé and Uribe [4] using a MIPF model incorporating a backward-looking interest-rate rule, which corresponds to the case where $n \rightarrow 1$ in (11).

${ }^{8}$ For details of the argument concerning the difference between the MIUF and MIPF approaches, see Feenstra [13] and Carlstrom and Fuerst [10].
} 
the steady state and obtain the following equations:

$$
\begin{gathered}
\dot{\hat{c}}(t)=[D \hat{\pi}(t-\theta)-\hat{\pi}(t)] c^{*}, \\
\dot{\hat{\pi}}(t)=\rho \hat{\pi}(t)-P_{2} D \hat{\pi}(t-\theta)-P_{1} \hat{c}(t),
\end{gathered}
$$

where $\hat{c}(t) \equiv c(t)-c^{*}, \quad \hat{\pi}(t) \equiv \pi(t)-\pi^{*}$, and $P_{1} \equiv$ $\frac{1-\alpha}{\alpha^{2}} \frac{\phi}{\eta} R^{*}\left(c^{*}\right)^{\frac{1-2 \alpha}{\alpha}}$.

Assuming the exponential functions of $\hat{c}(t)=C_{1} e^{\lambda t}$ and $\hat{\pi}(t)=C_{2} e^{\lambda t}$ as the solutions of this system and substituting these into system (17), we obtain

$$
\left[\begin{array}{cc}
\lambda & -\left(D e^{-\lambda \theta}-1\right) c^{*} \\
P_{1} & \lambda-\rho+P_{2} D e^{-\lambda \theta}
\end{array}\right]\left[\begin{array}{l}
\hat{c}(t) \\
\hat{\pi}(t)
\end{array}\right]=\left[\begin{array}{l}
0 \\
0
\end{array}\right]
$$

For non-trivial solutions to exist, the determinant of the left-hand side matrix must equal zero:

$\Delta_{2}(\lambda) \equiv \lambda^{2}-\rho \lambda-P_{1} c^{*}+\left(P_{2} D \lambda+P_{1} D c^{*}\right) e^{-\lambda \theta}=0$,

which is the characteristic equation of system (17).

An equation with an exponential term as in (18) is known to have infinite solutions. ${ }^{9}$ The two endogenous variables in system (16), $c$ and $\pi$, are jump variables. Therefore, if just two of the infinite number of roots have positive real parts, then the equilibrium is locally determinate. However, if the number of roots with positive real parts is less than two, the equilibrium is indeterminate; if it is greater than two, then an equilibrium does not exist (i.e., the steady state is unstable).

Considering the argument developed in Section 3.2, we assume the following condition:

\section{Assumption $4.1 \rho<P_{2} D$.}

In addition, in order to observe the stabilizing effect of lags, we assume that if a policy lag does not exist then equilibrium is indeterminate, even under an active monetary policy.

\section{Assumption 4.2 D $>1$.}

Based on these assumptions, we analyze the effects of a policy lag on local equilibrium determinacy. The procedures are given as follows ${ }^{10}$ :

(1) We characterize the points (if any) at which the equilibrium dynamics can change, i.e., points at which the real root of zero or the pure imaginary roots appear. These points are referred to as the crossing points.

(2) We reveal the directions of changes in the signs of the real parts of roots when $\theta$ crosses the crossing points.

\subsection{Crossing Points}

\subsubsection{Real Root of Zero}

Substituting $\lambda=0$ into (18), we obtain $\Delta_{2}(0)=$ $P_{1} c^{*}(D-1)=0$. This equality cannot hold as long as $D \neq 1$. Therefore, under Assumption 4.2, $\lambda=0$ cannot be a root and the signs of the real roots never change.

\footnotetext{
${ }^{9}$ See Chapter 3 in Bellman and Cooke [2].

${ }^{10} \mathrm{We}$ follow Matsumoto and Szidarovszky [17] for the methods of analysis.
}

\subsubsection{Pure Imaginary Roots}

Substituting $\lambda=i z$ (where $z=$ imaginary part $>0$; $i=\sqrt{-1}$ ) into $(18),{ }^{11}$ we obtain

$$
-z^{2}-\rho z i-P_{1} c^{*}+\left(P_{2} D z i+P_{1} D c^{*}\right) e^{-\theta z i}=0 .
$$

Applying Euler's formula $\left(\forall x \in \mathbb{R}, e^{ \pm i x}=\cos x \pm i \sin x\right)$ yields

$$
\begin{gathered}
-z^{2}-P_{1} c^{*}+P_{2} D z \sin \theta z+P_{1} D c^{*} \cos \theta z+i[-\rho z+ \\
\left.P_{2} D z \cos \theta z-P_{1} D c^{*} \sin \theta z\right]=0 .
\end{gathered}
$$

For this equality to hold, both the real and imaginary parts of this equation must equal zero; that is

$$
\begin{gathered}
D\left(P_{2} z \sin \theta z+P_{1} c^{*} \cos \theta z\right)=z^{2}+P_{1} c^{*} \\
D\left(P_{1} c^{*} \sin \theta z-P_{2} z \cos \theta z\right)=-\rho z
\end{gathered}
$$

Using (19) and (20), we can obtain

$$
\cos \theta z=\frac{z^{2}\left(P_{1} c^{*}+P_{2} \rho\right)+P_{1}^{2}\left(c^{*}\right)^{2}}{D\left(P_{1}^{2}\left(c^{*}\right)^{2}+P_{2}^{2} z^{2}\right)}
$$

where $2 \pi h<\theta z<2 \pi(1+h), h=0,1,2,3, \cdots$.

Furthermore, the sum of the square of (19) and (20) gives the following fourth degree equation of $z$ :

$$
z^{4}+\left(2 P_{1} c^{*}+\rho^{2}-P_{2}^{2} D^{2}\right) z^{2}+P_{1}^{2}\left(c^{*}\right)^{2}\left(1-D^{2}\right)=0 .
$$

Solving for $z^{2}$, we obtain

$$
Z_{ \pm}^{2}=\frac{-\left(2 P_{1} c^{*}+\rho^{2}-P_{2}^{2} D^{2}\right) \pm \sqrt{N}}{2}
$$

where $N \equiv\left(2 P_{1} c^{*}+\rho^{2}-P_{2}^{2} D^{2}\right)^{2}-4 P_{1}^{2}\left(c^{*}\right)^{2}\left(1-D^{2}\right)$.

Under Assumption 4.2, we obtain $-4 P_{1}^{2}\left(c^{*}\right)^{2}\left(1-D^{2}\right)>$ 0 . Therefore, $z_{+}^{2}>0$ and $z_{-}^{2}<0$. Substitute a real and positive value of $z$ (i.e., $z_{+}>0$ ) into (21) and solve for $\theta$ to obtain

$$
\theta_{h}=\frac{1}{z_{+}} \cos ^{-1}\left[\frac{z_{+}^{2}\left(P_{1} c^{*}+P_{2} \rho\right)+P_{1}^{2}\left(c^{*}\right)^{2}}{D\left(P_{1}^{2}\left(c^{*}\right)^{2}+P_{2}^{2} z_{+}^{2}\right)}\right], h=0,1,2,3, \cdots .
$$

Thus, an infinite number of values of $\theta$ (i.e., $\theta_{0}, \theta_{1}, \theta_{2}$, ...) that generate pure imaginary roots exist.

\subsection{Direction of Crossing}

This section reveals the directions of changes in the signs of the real parts of complex roots when $\theta$ crosses $\theta_{h}$. This direction is determined by the sign of $d \operatorname{Re}(\lambda) /\left.d \theta\right|_{\lambda=i z_{+}}$. If $d \operatorname{Re}(\lambda) /\left.d \theta\right|_{\lambda=i z_{+}}>0$ for any value of $h$, then the roots always intersect the imaginary axis of the complex plane from left to right with an increase in $\theta$, i.e., the number of roots with positive real parts increases at each time of crossing.

Incidentally, as demonstrated by Proposition 3.1, the signs of the real parts of all roots are negative when $\theta=0$. Therefore, based on continuity of roots, we can state that if $d \operatorname{Re}(\lambda) /\left.d \theta\right|_{\lambda=i z_{+}}>0$ for any value of $h$, then there are $2 h$

\footnotetext{
${ }^{11}$ Pure imaginary roots are always conjugated. Therefore, we can assume $z>0$ without loss of generality.
} 
complex roots with positive real parts in the region of $\theta \in\left(\theta_{h-1}, \theta_{h}\right)$ (where $\left.\theta_{-1}=0\right)$.

For convenience, we observe the sign of $\left.\operatorname{Re}(d \lambda / d \theta)^{-1}\right|_{\lambda=i z_{+}}$instead of $d \operatorname{Re}(\lambda) /\left.d \theta\right|_{\lambda=i z_{+}}$. Equation (18) demonstrates that the following inequality holds (see Appendix A.2):

$$
\left.\operatorname{Re}\left(\frac{d \lambda}{d \theta}\right)^{-1}\right|_{\lambda=i z_{+}}>0 .
$$

Therefore, we can state that $2 h$ complex roots with positive real parts exist in the region of $\theta \in\left(\theta_{h-1}, \theta_{h}\right)$ (where $\left.\theta_{-1}=0\right)$. We can thus offer the following proposition:

Proposition 4.1 Under the interest-rate rule in (13), if $\rho<P_{2} D$ and $D>1$, then an equilibrium is indeterminate for $\theta \in\left(0, \theta_{0}\right)$; it is locally determinate for $\theta \in\left(\theta_{0}, \theta_{1}\right)$, and nonexistent for $\theta \in\left(\theta_{1}, \infty\right)$.

This proposition implies that the central bank should seek a modest lag in its policy response in order to establish local equilibrium determinacy; if the lag is extremely large then equilibrium does not exist, whereas if it is too small then indeterminacy occurs.

\subsection{Numerical Example}

Let us consider a numerical example. On the basis of the parameter values shown in Table 1, we derive Fig. 2, which depicts the sets $\left(\theta_{h}, D\right)$ (where $\left.h=0,1,2\right)$ satisfying (23) on the $\theta-D$ plane. These are the crossing curves.

In the left-hand side region of the curve $\theta_{0}$, a root with positive real parts does not exist, and accordingly, the equilibrium is indeterminate. In the region between curves $\theta_{0}$ and $\theta_{1}$, exactly two roots with positive real parts exist, and hence, the equilibrium is locally determinate. Likewise, in the right-hand side region of curve $\theta_{1}$, at least four roots with positive real parts exist, and therefore, equilibrium does not exist.

For example, when $D=1.5$, the equilibrium is locally determinate for $\theta \in(0.157,0.786)$. This implies that the monetary policy lag that would achieve local equilibrium determinacy is $2-10$ weeks.

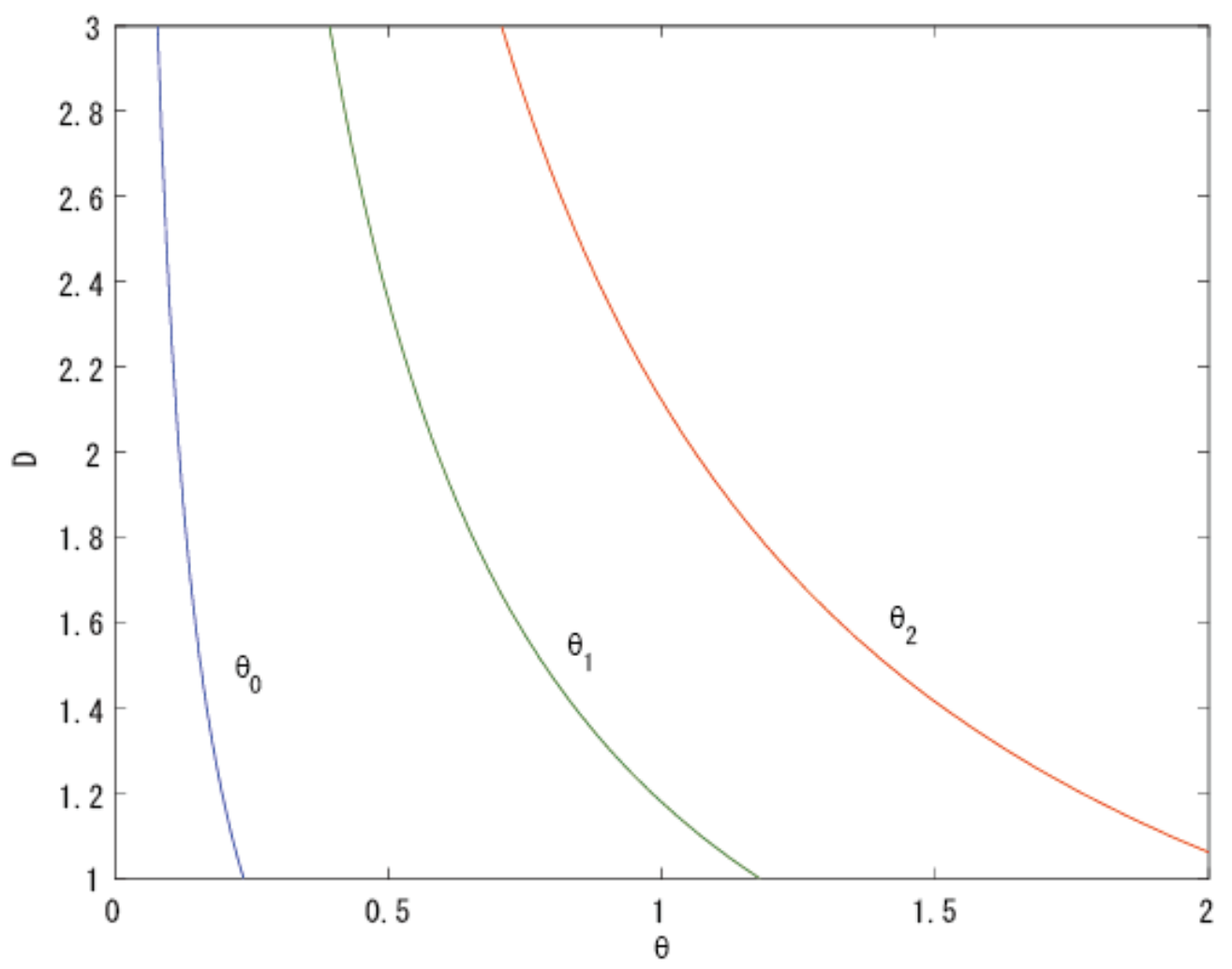

Figure 2. Crossing curves.

\section{Conclusion}

We have proposed a continuous-time NK framework incorporating a monetary policy rule that considers a lag in the central bank's response to economic fluctuations to examine local equilibrium determinacy.

In case of no policy lag, an equilibrium is indeterminate under the plausible parameter setup $\left(\rho<P_{2} D\right)$ even if a central bank's policy response is sufficiently active. However, in case of positive policy lag, local determinacy can be established if the policy stance is sufficiently active and the policy lag is moderate. If a lag is extremely large, then equilibrium does not exist; however, if it is too small, indeterminacy occurs. This result suggests that intentional control of the timing of policy implementation can have a stabilizing influence.

Thus, if a policy lag is extremely large, an economy will never attain the steady state. Therefore, we can also conclude that a policy lag can possibly be considered a factor in 
long-run instability.

\section{A. Appendix}

\section{A.1. Equilibrium Determinacy of System (14)}

The Jacobian matrix of system (14) evaluated at the steady state can be given as follows:

$$
J_{1}=\left[\begin{array}{cc}
0 & (D-1) c^{*} \\
-P_{1} & \rho-P_{2} D
\end{array}\right]
$$

where $P_{1} \equiv \frac{1-\alpha}{\alpha^{2}} \frac{\phi}{\eta} R^{*}\left(c^{*}\right)^{\frac{1-2 \alpha}{\alpha}}>0$ and $P_{2} \equiv \frac{\phi}{\eta \alpha}\left(c^{*}\right)^{\frac{1-\alpha}{\alpha}}>0$.

The characteristic equation of this system is given by

$$
\Delta_{1}(\lambda) \equiv\left|\lambda I-J_{1}\right|=\lambda^{2}+b_{1} \lambda+b_{2}=0 .
$$

where

$$
\begin{gathered}
b_{1}=-\operatorname{trace}\left(J_{1}\right)-\left(\rho-P_{2} D\right), \\
b_{2}=\operatorname{det}\left(J_{1}\right)=(D-1) P_{1} c^{*} .
\end{gathered}
$$

\section{Case with $D>1$}

We first consider the case in which $D>1$ (i.e., $b_{2}=$ $\operatorname{det}\left(J_{1}\right)>0$ ). If $\rho>P_{2} D$ (i.e., $-b_{1}=\operatorname{trace}\left(J_{1}\right)>0$ ), then (A.1) has two roots with positive real parts (Note that the value of trace equals the sum of roots and that of the determinant equals the product of the roots). Therefore, if $D>1$ and $\rho>P_{2} D$, then the equilibrium is locally determinate.

However, if $\rho<P_{2} D$ (i.e., $-b_{1}=\operatorname{trace}\left(J_{1}\right)<0$ ), then (A.1) has two roots with negative real parts. Therefore, the equilibrium is indeterminate.

\section{Case with $D<1$}

In this case, $b_{2}=\operatorname{det}\left(J_{1}\right)<0$. Therefore, (A.1) has one positive and one negative real root, and hence, the equilibrium is indeterminate.

\section{A.2. Direction of Crossing}

Differentiating (18) with respect to $\theta$, we obtain

$$
\begin{gathered}
\left\{2 \lambda-\rho+P_{2} D e^{-\lambda \theta}-\left(P_{2} D \lambda+P_{1} D c^{*}\right) \theta e^{-\lambda \theta}\right\} \frac{d \lambda}{d \theta}= \\
\left(P_{2} D \lambda+P_{1} D c^{*}\right) \lambda e^{-\theta \lambda}
\end{gathered}
$$

or equivalently

$$
\left(\frac{d \lambda}{d \theta}\right)^{-1}=\frac{(2 \lambda-\rho) e^{\theta \lambda}+P_{2} D}{\left(P_{2} D \lambda+P_{1} D c^{*}\right) \lambda}-\frac{\theta}{\lambda}
$$

where $e^{\theta \lambda}$ is derived from (18) by

$$
e^{\theta \lambda}=\frac{P_{2} D \lambda+P_{1} D c^{*}}{-\lambda^{2}+\rho \lambda+P_{1} c^{*}}
$$

Therefore, we obtain

$$
\begin{gathered}
\operatorname{sign}\left[\frac{d \operatorname{Re}(\lambda)}{d \theta}\right]_{\lambda=i z_{+}}=\operatorname{sign}\left[\left(\frac{d \lambda}{d \theta}\right)^{-1}\right]_{\lambda=i z_{+}}= \\
\operatorname{sign}\left[\operatorname{Re}\left\{\frac{2 \lambda-\rho}{\lambda\left(-\lambda^{2}+\rho \lambda+P_{1} c^{*}\right)}+\frac{P_{2} D}{\lambda\left(P_{2} D \lambda+P_{1} D c^{*}\right)}-\frac{\theta}{\lambda}\right\}\right]_{\lambda=i z_{+}}=
\end{gathered}
$$

$$
\operatorname{sign}\left[\operatorname{Re}\left\{\frac{2 z_{+} i-\rho}{z_{+} i\left(z_{+}^{2}+\rho z_{+} i+P_{1} c^{*}\right)}+\frac{P_{2} D}{z_{+} i\left(P_{2} D z_{+} i+P_{1} D c^{*}\right)}-\frac{\theta_{h}}{i z_{+}}\right\}\right] .
$$

The last term of the right-hand side of the bottom equality, $-\theta_{h} / i z_{+}$, is obviously imaginary and therefore can be ignored. To decompose the other terms into real and imaginary parts, we define

$$
\begin{aligned}
& u \equiv \frac{2 z_{+} i-\rho}{z_{+} i\left(z_{+}^{2}+\rho z_{+} i+P_{1} c^{*}\right)}, \\
& v \equiv \frac{P_{2} D}{z_{+} i\left(P_{2} D z_{+} i+P_{1} D c^{*}\right)},
\end{aligned}
$$

and obtain

$$
\begin{aligned}
& \operatorname{Re}(u)=\frac{\rho^{2}+2\left(z_{+}^{2}+P_{1} c^{*}\right)}{\rho^{2} z_{+}^{2}+\left(z_{+}^{2}+P_{1} c^{*}\right)^{2}}, \\
& \operatorname{Re}(v)=-\frac{P_{2}^{2}}{P_{2}^{2} z_{+}^{2}+P_{1}^{2}\left(c^{*}\right)^{2}} .
\end{aligned}
$$

Using these expressions, we obtain

$$
\begin{gathered}
\operatorname{sign}\left[\frac{d \operatorname{Re}(\lambda)}{d \theta}\right]_{\lambda=i z_{+}}=\operatorname{sign}[\operatorname{Re}(u)+\operatorname{Re}(v)] \\
=\operatorname{sign}\left[\frac{P_{1}^{2}\left(c^{*}\right)^{2} \rho^{2}+P_{2}^{2} z_{+}^{4}+2\left(z_{+}^{2}+P_{1} c^{*}\right) P_{1}^{2}\left(c^{*}\right)^{2}-P_{1}^{2} P_{2}^{2}\left(c^{*}\right)^{2}}{\left[\rho^{2} z_{+}^{2}+\left(z_{+}^{2}+P_{1} c^{*}\right)^{2}\right]\left[P_{2}^{2} z_{+}^{2}+P_{1}^{2}\left(c^{*}\right)^{2}\right]}\right] .
\end{gathered}
$$

The denominator of the right-hand side of the second equality is obviously imaginary. Therefore, we only have to observe the sign of the numerator. Substitute (22) into $2 z_{+}^{2}$ after dividing the numerator by $P_{1}^{2}\left(c^{*}\right)^{2}>0$ to obtain

$$
\frac{P_{2}^{2} z_{+}^{4}}{P_{1}^{2}\left(c^{*}\right)^{2}}+P_{2}^{2}\left(D^{2}-1\right)+\sqrt{N}>0 \text {. }
$$

\section{Acknowledgments}

This paper is dedicated to Professor Toshikazu Ito on the occasion of his retirement from Ryukoku University.

\section{References}

[1] T. Asada and H. Yoshida, "Stability, instability and complex behavior in macrodynamic models with policy lag," Discrete Dynamics in Nature and Society, vol. 5(4), pp.281-295, 2001.

[2] R. E. Bellman and K. L. Cooke, Differential-Difference Equations, Academic Press, New York, 1963.

[3] J. Benhabib, S. Schmitt-Grohé, and M. Uribe, "Monetary policy and multiple equilibria," American Economic Review, vol. 91(1), pp.167-186, 2001.

[4] J. Benhabib, S. Schmitt-Grohé, and M. Uribe, "Backward-looking interest-rate rules, interest-rate smoothing, and macroeconomic instability," Journal of Money, Credit and Banking, vol. 35(6), pp.1379-1412, 2003.

[5] B. S. Bernanke and M. Woodford, "Inflation forecasts and monetary policy," Journal of Money, Credit and Banking, vol. 29(4), pp.653-684, 1997. 
[6] F. O. Bilbiie, "Limited asset markets participation, monetary policy and (inverted) aggregate demand logic," Journal of Economic Theory, vol. 140(1), pp.162-196, 2008.

[7] O. J. Blanchard and N. Kiyotaki, "Monopolistic competition and the effects of aggregate demand," American Economic Review, vol. 77(4), pp.647-666, 1987.

[8] E. F. Buffie, “The Taylor principle fights back, part I,” Journal of Economic Dynamics and Control, vol. 37, pp.2771-2795, 2013.

[9] C. T. Carlstrom and T. S. Fuerst, "Forward-looking versus backward-looking Taylor rules," FRB Cleveland, no. 0009, 2000 .

[10] C. T. Carlstrom and T. S. Fuerst, "Comment on "Backward-looking interest-rate rules, interest-rate smoothing, and macroeconomic instability" by Jess Benhabib," Journal of Money, Credit and Banking, vol. 35(6), pp.1413-1423, 2003.

[11] C. T. Carlstrom and T. S. Fuerst, "Asset prices, nominal rigidities, and monetary policy," Review of Economic Dynamics, vol. 10(2), pp.256-275, 2007.

[12] A. K. Dixit and J. E. Stiglitz, "Monopolistic competition and optimum product diversity," American Economic Review, vol. 67(3), pp.297-308, 1977.

[13] R. C. Feenstra, "Functional equivalence between liquidity costs and the utility of money," Journal of Monetary Economics, vol. 17(2), pp.271-291, 1986.

[14] M. Friedman, "A monetary and fiscal framework for economic stability," American Economic Review, vol. 38(3), pp.245-264, 1948.

[15] J. Galí, Monetary Policy, Inflation, and the Business Cycle: An Introduction to the New Keynesian Framework, Princeton University Press, 2008.
[16] G. Gandolfo, Economic Dynamics, 4th ed., Springer-Verlag, 2010.

[17] A. Matsumoto and F. Szidarovszky, "An elementary study of a class of dynamic systems with two time delays," Cubo (Тетисо), vol. 14(3), pp.103-113, 2012.

[18] J. J. Rotemberg, "Sticky prices in the United States," Journal of Political Economy, vol. 90(6), pp.1187-1211, 1982.

[19] J. B. Taylor, "Discretion versus policy rules in practice," Carnegie-Rochester Conference Series on Public Policy, vol. 39, pp.195-214, North-Holland, 1993.

[20] E. Tsuzuki, "Unimodality of a weight function in backward-looking interest-rate rules and determinacy of equilibrium," Keizaironsyu, vol. 100, pp.147-171, The Economics Society, Daito Bunka University, 2013.

[21] E. Tsuzuki, "A New Keynesian model with delay: Monetary policy lag and determinacy of equilibrium," Economic Analysis and Policy, vol. 44(3), pp.279-291, 2014.

[22] E. Tsuzuki and T. Inoue, "Technological change and monetary policy in a sticky-price model," Research in Economics, vol. 65(3), pp.180-194, 2011.

[23] C. E. Walsh, Monetary Theory and Policy, 3rd ed., MIT Press, 2010.

[24] M. Woodford, Interest and Prices: Foundations of a Theory of Monetary Policy, Princeton University Press, 2003.

[25] H. Yoshida and T. Asada, "Dynamic analysis of policy lag in a Keynes-Goodwin model: Stability, instability, cycles and chaos," Journal of Economic Behavior and Organization, vol. 62(3), pp.441-469, 2007. 